\title{
UNKNOWN LOAD MEASUREMENT IN HACK SAW MACHINE
}

\author{
Avilasha B G ${ }^{1}$, Dr. Ramakrishna D $S^{2}$ \\ ${ }^{1}$ Lecturer, Mechanical Department, APS College of engineering, Bangalore, Karnataka, India \\ ${ }^{2}$ Professor \& Head, Mechanical Department, JNN College of engineering Shimoga, Karnataka, India
}

\begin{abstract}
The measurement of load acting on machines and structures is important from many considerations. Accurate weighing of commodities, applying known load on specimens being tested for strength, safe operation of material handling equipment such as crane, determination of operating loads are some examples. When the load or forces are to be measured, a load cell is to be placed in the load path. Many times, it is not feasible to insert the load cell in the load path. In such cases, using the machine member themselves for measuring load will be advantageous. This dissertation work involves study Hack Saw machine where the load measurement is essential. Investigation is carried out to study the feasibility of using the member of the machine itself as load sensing member. The load measurement involves identification of critical component in the load path. While the process of load measurement is not straightforward in case where the known load is cannot be applied, inverse FEM is to be adopted for the case where applied load is not known. Once the critical component in the load path is identified, electrical resistance strain gauges are mounted in an appropriate fashion to get maximum output for an applied load. The dynamic strain was recorded using the LABVIEW software. The finite element analysis done for hacksaw machine with proper boundary conditions and the strain data are taken for series of loads and then these values are compared with the experimental strain value and the unknown load was estimated.
\end{abstract}

Keywords: load, strain gauge, Hack Saw Machine, load meter. FEM

\section{INTRODUCTION}

The load can be measured in different ways and this load may be static or dynamic. Most commonly used method for load measurement is load cells. The principle working of load cells are very important in load measurement by using strain gauges. When loads or forces are to be measured, a load cell is to be placed in the load path. Many times it is not feasible to insert a load cell in the load path, in such cases using the machine members themselves for measuring load will be advantageous.

Many researchers have been done experiment on load measurement in the machine members. Inverse load sensing method for finding a line load distribution, the feasibility of the method, especially for rotating beams is evaluated. The strain measurement of beam like structures can be utilized in order to solve the actuating line load distribution. The Inverse load sensing method is first verified in two experimental cases of static point forces acting on beam like structure. finally method is tested on real dynamic application of pilot rolls press, strain gauges are installed on to the inner surface of one of the roller and strain data recorded during run and inverse load sensing the load is estimated.[1].

The determination of impact force for beam and plate type of structures subjected to transverse impacts. Strain gauges were used in his experiment to sense the strain responses at selected locations on the specimens. The force/strain relation for the transverse impact of beam and plate were established in the time domain for beam, and frequency domain for the plates. Inversion by the use of fast Fourier transform (FFT) was shown to determine the force history [2].

Identification of external structural load by measuring harmonic responses. In many practical situations, it is difficult to perform direct measurements or calculations of the external forces acting on an existing vibrating structure. Instead, the structural response may be measured and the position and magnitude of the exciting forces be calculated from the measured response [3].

A load cell is a transducer that converts mechanical force into electrical signals. There are many different types of load cells that operate in different ways, but the most commonly used load cell today is the strain gauge (or strain gauge) load cell. As their name implies, strain gauge load cells use an array of strain gages to measure the deformation of a structural member and convert it into an electrical signal. But Many times it is not feasible to insert a load cell in the load path, in such cases using the machine members themselves for measuring load will be advantageous. 
The load measurement in case of dynamic load or where the known load cannot be apply on the machines and structures, the inverse finite element method is incorporated in the load measurement. In the present work for the dynamic load measurement, the reciprocating type power hacksaw has been studied. The gauges mounted on the $\mathrm{U}$ body of machine and the dynamic strain was recorded using the LABVIEW software. The finite element analysis done for hacksaw machine with proper boundary conditions and the strain data are taken for series of loads and then these values are compared with the experimental strain value and the unknown load was estimated. The load estimation in power hacksaw will be useful for the

The power hacksaw machines are also known as heavy-duty power hacksaw or production hack Saws. These are heavier in construction and are provided with some additional accessories. Materials like wood and metals are often cut using sawing machines. Metal sawing is like any other metal processing method and it is governed by similar cutting requirements. Sawing is used because of its some characteristics advantages like speed of cutting, low wastage of material, good quality of dimensional accuracy and low power consumption.

During the dissertation work the Hack Saw Frame of the Hack Saw machine has been analyzed to explore the possibility of using a member of the hacksaw machine itself as load sensing member, this drastically helps to optimize the hacksaw machine.

\section{NEED OF LOAD MEASUREMENT}

Load measurement is an important technique enabling machine health monitoring and fault localization, however direct measurement is usually difficult or impossible. The load measurement is very important aspects in design of machines and structures. The load is basic parameter to design the machines.

The main purpose of load measurement in machines and structures is design of machines components, control purpose and optimization point of view. All machines, structures or every equipments designed based on the estimated load. Once the applied load exceeds the estimated load, the machine may fail suddenly due to overloading. In machineries, the designed load is different from the practically applied load, in these situations the exact load acting on the machines and structures should be known for the purpose of safety and optimization.

The load measurement also helps in optimization of machine parts, the exact load applied on the components has to be known in case of optimization. By knowing exact load, the component dimensions and material properties may be designed. Optimization reduces the material and cost involved in the design. The load estimation in power hacksaw will be useful for the optimization and safety of the machine.

\section{STRAIN GAUGE}

There are several methods of measuring strain, the most common is with a strain gauge, a device whose electrical resistance varies in proportion to the amount of strain in the device. The most widely used gauge is the bonded metallic strain gauge as shown in Figure-1. The strain gauges are available in different types such as mechanical gauges, optical, interferometric type gauges, electrical gauges, magnetic gauges, acoustic gauges, pneumatic gauges, photo stress gauges. Most commonly used strain gauges are electrical strain gauges.

In electrical resistance gauges, again there are different types of gauges available they are inductance, capacitance, resistance, piezoelectric and piezoresistive gauges. In these, most popularly used gauges for the load measurement are resistance strain gauges. Further, the types of resistive strain gauges are unbounded gauges in that nonmetallic type and metallic type gauges, bonded strain gauges in that wire type, foil type gauges. The foil type gauges are more sensitive to the deformation of the materials and they are used for load measurement. Shown in fig. 1 with the reference of text book.

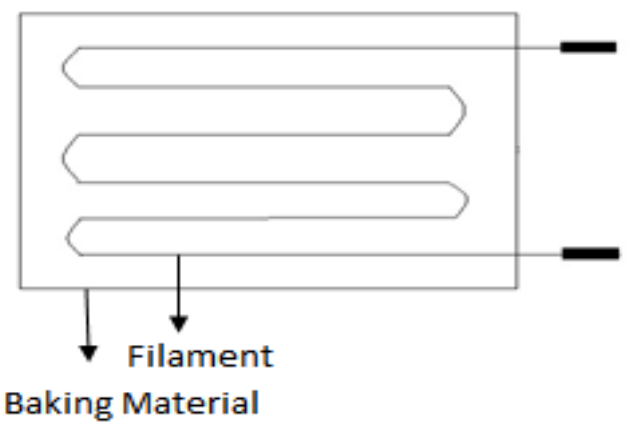

Fig-1: strain gauges 


\section{FEM ANALYSIS AND EXPERIMENT}

The finite element analysis carried out for hack saw machine member and the critical locations have been found. The element used for meshing was 4 node tetra 287, Four nodes having four degrees of freedom at each node define the element, three translations in the nodal $\mathrm{x}, \mathrm{y}$, and $\mathrm{z}$ directions, and one hydrostatic pressure (HDSP) for all materials and the material used was cast iron. The boundary conditions used are, $\mathrm{z}$ direction is fixed at blade center, $\mathrm{x}$ direction if fixed on $\mathrm{U}$ body. The material properties used are $\mathrm{E}=170 \mathrm{GPA}$, density= $400 \mathrm{~kg} / \mathrm{m} 3$. The strain plot of the hack saw machine is shown in fig -2

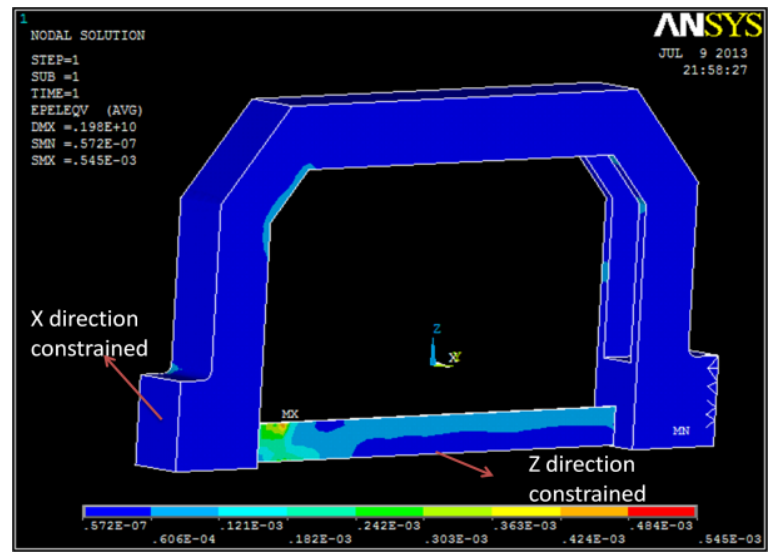

Fig-2: FEM Analysis

The strain gauges are mounted on the hacksaw machine member; the location of the strain gauges is as shown in fig 5.1.2. The side column of the hacksaw member will be under compression and due to the reaction force from the material, this reaction force tries to bend the column, so the column experience both compression as well as bending

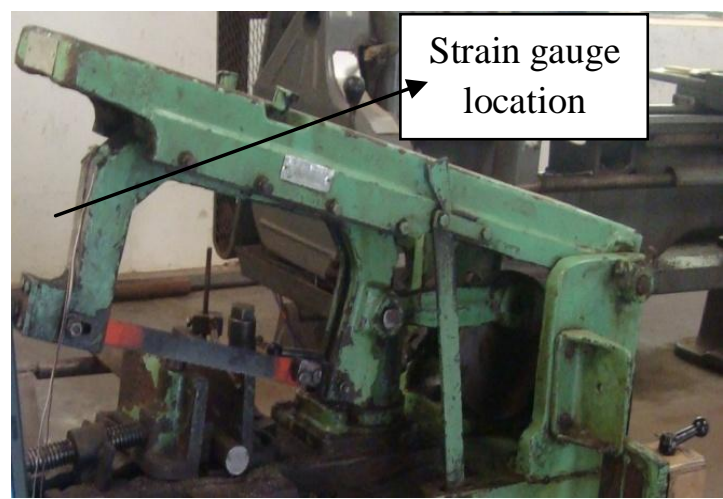

Fig -3: Location of Strain Gauge

\subsection{Experiment}

The strain data are taken by using LABVIEW, because the load applied is continuous and dynamic in nature. The strain gauge data acquisition 9219 was used to measure the peak strain while material is cut in the forward stroke. The FEM analysis was carried out for series of loads. The maximum strain value was taken experimentally when the material was cut. The experimental values are compared with the FEM strain. When the error is minimum then respective force will be applied force on the material. The experimental set up is as shown in fig 4 .

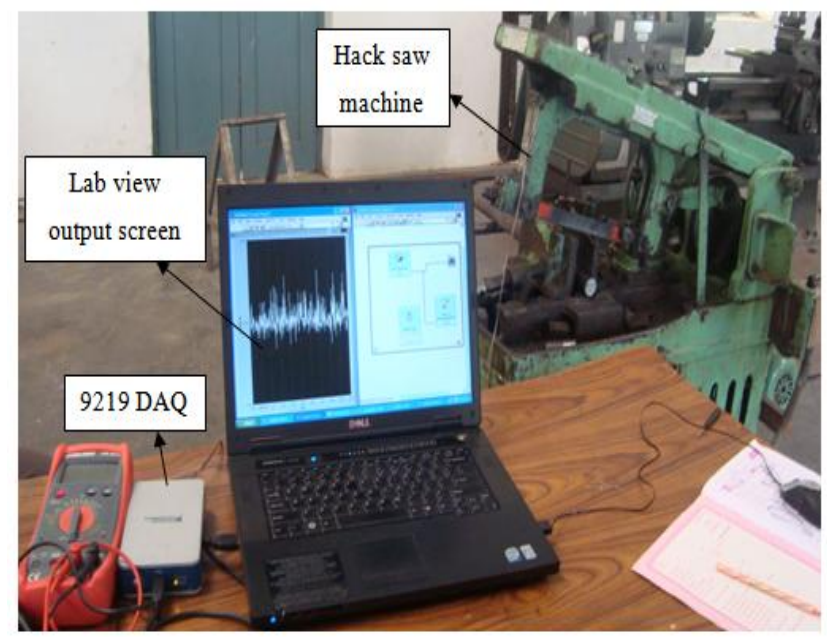

Fig-4: Experimental Set Up

The block diagram is used to record the strain values from the machine or structures in lab view software. The block diagram to read the strain is shown in the fig 5 .

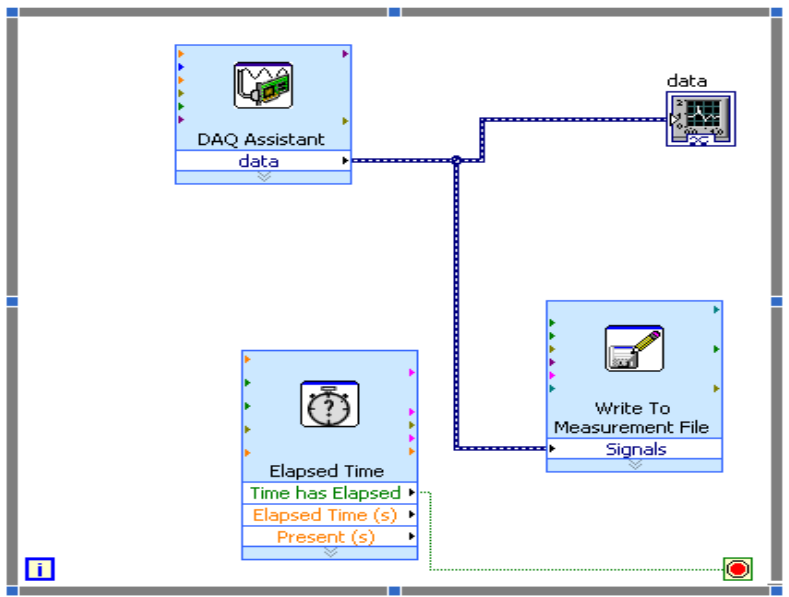

Fig-5: Circuit for Strain Measurement 
The experiment was conducted for cast iron material and mild steel material. When the cast iron material was cut, the maximum strain was recorded by using the LABVIEW software. In the same way the data are recorded when the material mild steel was cut.

When the cast iron was cut, the values are recorded and the graph is plotted. The LABVIEW output window when the maximum force was applied on the material is shown in fig-6.The material will cut in the forward stroke of the machine. The maximum strain will be in forward stroke. When the more force is applied on the material to cut, in that situation the value will be maximum

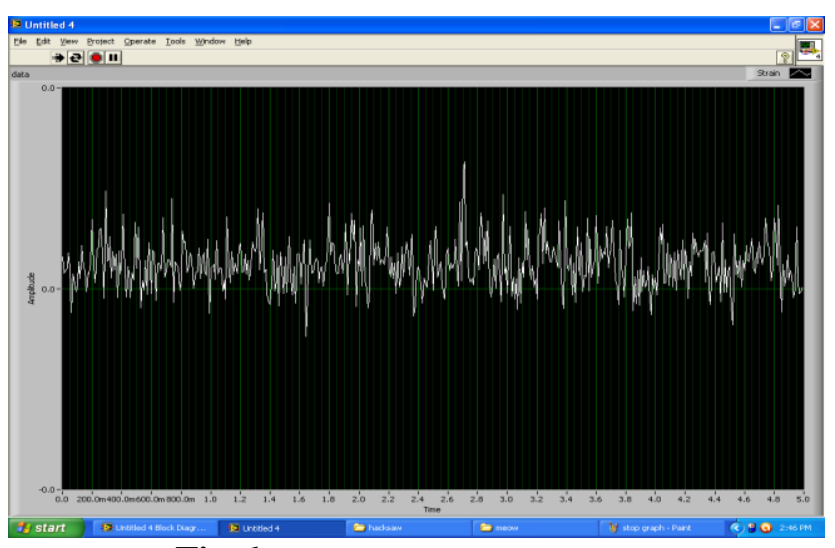

Fig-6: The LABVIEW Output

The numbers of values are recorded from lab view software. These values are taken and the maximum strain value of the machine was taken by plotting the graph. The maximum peak value for cast iron is 59 micro strains. This value is taken and compared with the finite element analysis strain values. This is shown in fig 7

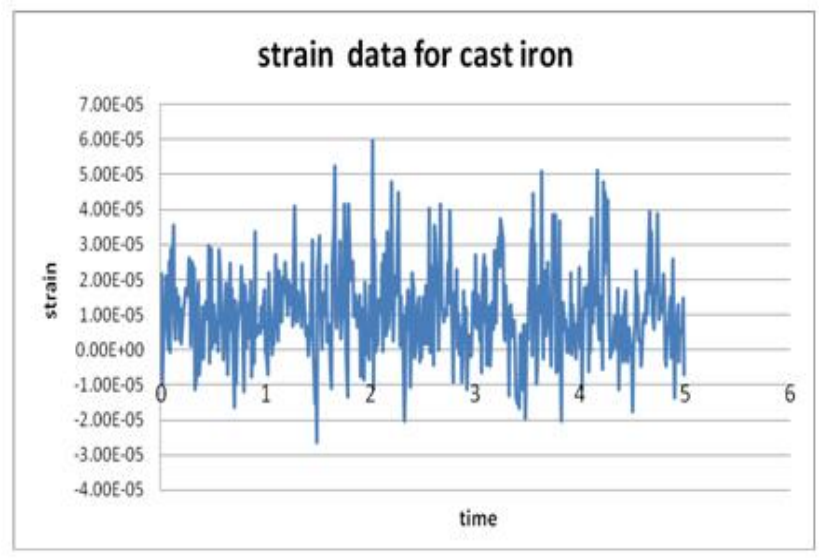

\section{RESULT AND DISCUSSIONS}

The estimation of load in power hacksaw machine has carried out by using the inverse FEM method, the experimental peak value of the strain was recorded by using the LABVIWE software. The maximum value of the strain occurs at the maximum force applied on the material to cut.

The maximum value was taken from experimental vales. Finite element analysis carried out for hacksaw machine by considering the proper boundary conditions; the readings are taken from FEM for series of load, the experimental and finite element readings by taking difference of both values and the error is calculated. The minimum error has found and the respective load is the exact load applied on the material to cut. The experimental value is 59 micro strains. Table- 1 shows the estimation of load.

Table-1: Estimated Load

\begin{tabular}{|c|c|c|}
\hline $\begin{array}{c}\text { Load } \\
\mathbf{N}\end{array}$ & $\begin{array}{c}\text { FEM Strain } \\
\boldsymbol{\mu \varepsilon}\end{array}$ & Error \% \\
\hline 400 & 44 & 34 \\
\hline 450 & 49 & 20 \\
\hline 500 & 55 & 7.27 \\
\hline $\mathbf{5 5 0}$ & $\mathbf{6 0}$ & $\mathbf{1 . 6 6}$ \\
\hline 600 & 66 & 10.60 \\
\hline 650 & 72 & 18.055 \\
\hline 700 & 78 & 24.35 \\
\hline 750 & 83 & 28.91 \\
\hline 800 & 89 & 33.70 \\
\hline
\end{tabular}

The minimum error is 1.66 so the estimated load is $550 \mathrm{~N}$ or $56 \mathrm{~kg}$. The $550 \mathrm{~N}$ was applied on the material to cut the cast iron. Depending upon the dimension of the material applied force may change. In the Present work, the square section bar was taken with dimensions of $50^{2} \mathrm{~mm}$. Fig- 8 shows the error $\mathrm{v} / \mathrm{s}$ load plot, for $550 \mathrm{~N}$ loads, the error is minimum, from inverse FEM analysis the minimum error load will be the estimated load for the machine

Fig-7: Maximum Strain Value 


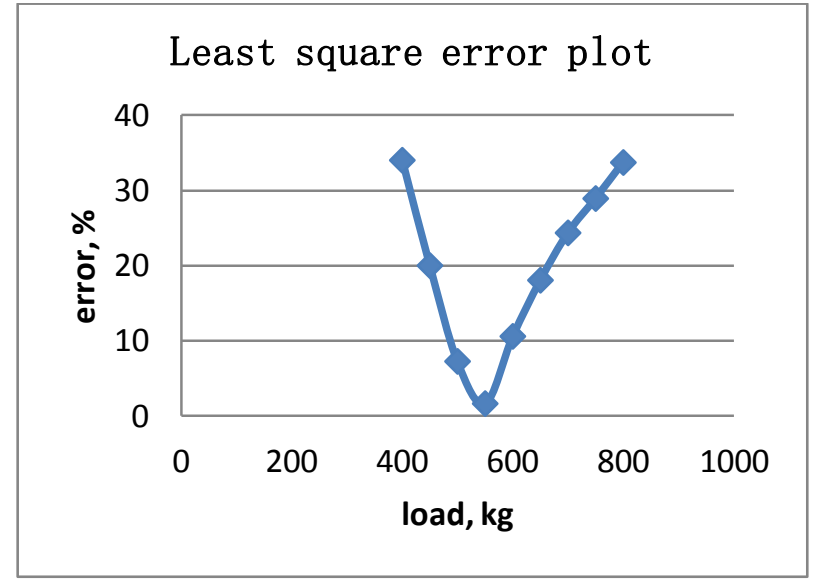

Fig-8: Error Graph

For dynamic case study of load measurement, the power hacksaw machine has been studied. During cutting operation in hacksaw machine, it is difficult to estimate the load on the blade and the machine members. Therefore, inverse finite element method can be used for measurement of load in case of hacksaw machine. The experimental peak strain was compared with the finite element analysis strain data. The minimum error was found and the force is estimated.

\section{CONCLUSION}

Measurement of load acting on machines and structures is important from many considerations. Accurate weighing of commodities, the machines and structures are designed based on the forces acting on them, in some situation, the forces can be directly measured, and in some critical situation, the forces acting on them are difficult to measure. The load cells are difficult to install on load path in some applications for load measurement, this can be resolve by using the machine component itself as load sensor. This method drastically reduces the cost involved in designing the separate load cell and accessories.

In every machinery, there is a huge necessity of load measurement. From the results of the experiment, it can be concluded that the load meter is very essential for load measurement when compared to load cell due to direct incorporation of strain gauges on machines and structures, which gives better results. To study the feasibility of using a component of the machine as load sensing member, different applications have been studied.
The dynamic load measurement have been studied on power hacksaw machine. In hacksaw machine, the cutting of material takes place in forward stroke. The load that is estimated from hacksaw can be used for the machine optimization purpose and safety of machine. This Maximum load applied on the machine can be estimated by using inverse FEM method .The maximum load applied on the blade while cutting the cast iron was estimated, the force is $550 \mathrm{~N}$.

\section{REFERENCES}

[1] Antti-jussi romppanen "Inverse load sensing method for finding a line load distribution" Tampere University of technology, $31^{\text {st }}$ of October.

[2] J.F Doyle professor."Determine the impact force for beam and plate type of structures subjected to transverse impacts." Exp.mech,27(10), 68,1987.

[3] S.E.S. Karlsson "Discussed an identification of external structural load by measuring harmonic responses." Division of Solid Mechanics, Chalmers University of Technology, S-412 96 Gothenburg, Sweden

[4] Nagraj M harihar "Inverse finite element approach to determine the static and dynamic forces acting on vehicle model" Mtech project 2010

[5] Ravinarayan R.Rao "force estimation on a mechanical member by inverse finite element approach "Mtech project 2008

[6] G.R.Liu and X.HAN "Computational inverse finite element method in nondestructive evaluation, using forward and inverse problems."

[7] Xing-line guo "Inverse pseudo excitation method to identification of random loading for structures subjected to stationary random excitation" International Journal of Computational Methods Vol. 8, No. 4 (2011) 667World Scientific Publishing Company

\section{BIOGRAPHIES}

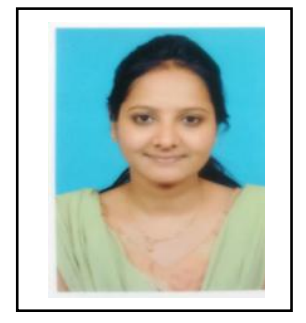

Lecturer APS College of Engineering, Bangalore. Mechanical Department M-tech, Design Engineering 